\title{
A Study on Serum Uric Acid Level in Type II Diabetes Mellitus
}

\author{
KASHIF ALI SAMIN ${ }^{1}$, KHALIL ULLAH ${ }^{2}$, MUHAMMAD IKRAM SHAH ${ }^{3}$, ABIDAMATEEN ANSARI ${ }^{4}$, SADIA KHALIL ${ }^{5}$, MARYAM \\ SAEED 6 \\ ${ }^{1}$ Assistant Professor Family Medicine, Khyber Medical University, Peshawar \\ ${ }^{2}$ Internal Medicine Physician, Amjad Kaka khel Clinic, Mardan \\ ${ }^{3}$ Assistant Professor (Medicine), Jinnah Medical College, Peshawar \\ ${ }^{4}$ Assistant Professor (Medicine)Al Nafees Medical College and Hospital, Lahore \\ ${ }^{5,6}$ MPhil Trainee, Senior Demonstrator Biochemistry, Shaikh Zayed Medical Complex/Post Graduate Medical Institute, Lahore \\ Corresponding Author: Dr. Kashif Ali Samin, Email: kashif@kmu.edu.pk, Cell: +923009590555
}

\begin{abstract}
Background and Aim: Morbidity and mortality from non-communicable diseases, particularly diabetes are increasing rapidly in Pakistan, the prevalence has reached $17.1 \%$. A strong association has been witnessed between type II diabetes mellitus with atherosclerosis and serum uric acid level. The current study aim was to assess the levels of serum uric acid in type II diabetes mellitus.

Materials and Methods: This cross-sectional study was carried out on 85 diagnosed patients of type II diabetes mellitus in Diabetes hospital, Peshawar and the Department of General Medicine, Shaikh Zayed Medical Complex, Lahore during the period from March 2020 to August 2020. Type II diabetes mellitus (DM) diagnosed patients 85 and healthy control 30 were evaluated in this study. The level of hyperuricemia was defined for women $>6 \mathrm{mg} / \mathrm{dl}$ and men $>7 \mathrm{mg} / \mathrm{dl}$ in men.

Results: In this study, a total of 85 diabetic diagnosed patients and 30 healthy controls were enrolled. No significant differences were there in the baseline characteristics like anthropometric and socio-demographic parameters. The mean age for diagnosed and control cases was $58.6 \pm 8.7$ and $56.5 \pm 7.6$ years with an age range of 40 and 80 years. Hyperuricemia proportion among diabetic patients was $12.13 \%$ while none of the control cases had hyperuricemia. The uric acid means level increased from $4.29 \pm 0.81 \mathrm{mg} / \mathrm{dl}$ with a diabetic duration between 3 and 4 years to $4.59 \pm 0.99 \mathrm{mg} / \mathrm{dl}$ with a diabetic duration of 5 to 7 years. Furthermore, mean serum uric acid level reached $6.50 \pm 1.08$ in cases with diabetic duration 8 to 12 years. Statistically, a significant association was found between diabetic duration and serum uric acid. Also, a positive correlation was found in hyperlipidemia, serum uric acid levels, and hypertension.

Conclusion: In diabetic patients serum uric acid levels were found to be significantly higher. Diabetic patients had hypertension, elevated serum uric acid levels, and high triglycerides with dyslipidemia. The rise in serum uric acid levels is proportional to the duration of diabetes.
\end{abstract}

Keywords: Serum uric acid, Type 2 diabetes mellitus, Hypertension.

\section{INTRODUCTION}

Morbidity and mortality from non-communicable diseases, particularly diabetes are increasing rapidly in Pakistan, the prevalence has reached $17.1 \%$. A strong association has been witnessed between type II diabetes mellitus with atherosclerosis and serum uric acid level [1,2]. Diabetes mellitus and metabolic syndrome (MS) is highly associated with insulin resistance state. Hyperlipidemia, hypertension, hyperglycemia, and hyperinsulinemia are the major metabolic syndrome players. This quartet has demonstrated independent risk factors and as a deadly member for Coronary heart disease (CHD) and accelerate both non-diabetic atherscoleropathy and MS-related atherscoleropathy in a synergistic manner and type II diabetes mellitus [3, 4]. Likewise, four parameters such as highly sensitive C-reactive protein, ROS, hyperuricemia, and hyperhomocysteinemia play a vital role in syndrome expansion reported in a study [5]. Subsequently, atherosclerosis's higher risk needs to be identified in the population as recommended screening method for type II diabetes mellitus [6]. A strong association between risk factors for cardiovascular disease and serum uric acid has been demonstrated [7].

Type II diabetes mellitus and related complications are increasing worldwide which contributes significantly to morbidity and mortality [8]. One associated complication is diabetic peripheral neuropathy (DPN) which adversely affects the quality of life in turn leads to disability and mortality. Additionally, it contributes to cardiovascular disease subsequent increased risks for mortality [9]. Number of factors such as dyslipidemia (DLP), smoking, plasma homo-cysteine levels, hyperglycemia duration, and hypertension (HTN) are associated with DPN pathogenesis. Oxidative stress, non-enzymaticglycation, polyol pathway, and free radical are the factors for molecular etiology [10]. DPN-associated risk factors identification might explain the new therapy about DPN development. Multiple vascular complications are caused by hyperuricemia as reported in previous studies [11, 12]. Given the paucity of research on the subject in Pakistan, an attempt was made to investigate the type 2 diabetes mellitus and the level of serum uric acid in it, as well as the relationship between risk factors such as obesity, hypertension, smoking, and dyslipidemia for cardiovascular disease and serum uric acid levels.

\section{MATERIALS AND METHODS}

This cross-sectional study was carried out on 85 diagnosed patients of type II diabetes mellitus inDiabetes hospital, Peshawar and the Department of General Medicine, Shaikh Zayed Medical Complex, Lahore during the period from March 2020 to August 2020. Eighty five (85) patients of Type II diabetes mellitus (DM) and healthy control 30 were evaluated in this study. The level of hyperuricemia 
was defined for women $>6 \mathrm{mg} / \mathrm{dl}$ and men $>7 \mathrm{mg} / \mathrm{dl}$ in men. Type-II diabetes mellitus patients of either gender irrespective of their diabetic duration and glycemic status and had age between 40 and 80 years were enrolled in this study. Patients with renal failure, chain smoker, long-term steroids and diuretics, chemotherapy and antimetabolic drugs users, renal transplant patients, pulmonary tuberculosis, and Pregnancy and lactating mothers were excluded from this study. The institutional ethical committee provided ethical approval. Each individual provided written informed consent, and study confidentiality was maintained throughout the investigation.

Prior to informed consent, demographic data from controls and patients were gathered on pre-designed proforma. Socio-demographic factors such as age and gender, family history, diabetes duration, and smoking history data were collected. Anthropometric data such as weight, height, WHR, and BMl were recorded through physical examination. Clinical parameters such as diastolic and systolic pressure were recorded. The blood specimen of $10 \mathrm{ml}$ was collected and assessed through the laboratory of postprandial sugar levels of blood using glucosoxidaseperoxidase estimation method, lipid profile, and manual blood urea was estimated through diacetyl monoxime method. The alkaline picrate method was utilized for the estimation of serum creatinine levels. An independent sample t-test was carried out on both groups in order to compare the quantities variables. The Chisquare test compared the categorical variables with $p$ value $<0.05$ as statistical significance. Statistical analysis was carried out in SPSS version 21.

\section{RESULTS}

In this study, a total of 85 diabetic diagnosed patients and 30 healthy controls were enrolled. No significant differences were there in the baseline characteristics like anthropometric and socio-demographic parameters. The mean age for diagnosed and control cases was $58.6 \pm 8.7$ and $56.5 \pm 7.6$ years with an age range of 40 and 80 years. Hyperuricemia proportion among diabetic patients was $12.13 \%$ while none of the control cases had hyperuricemia. The uric acid means level increased from $4.29 \pm 0.81 \mathrm{mg} / \mathrm{dl}$ with a diabetic duration between 3 and 4 years to $4.59 \pm 0.99 \mathrm{mg} / \mathrm{dl}$ with a diabetic duration of 5 to 7 years. Furthermore, mean serum uric acid level reached $6.50 \pm 1.08$ in cases with diabetic duration 8 to 12 years. Statistically, a significant association was found between diabetic duration and serum uric acid. Also, a positive correlation was found in hyperlipidemia, serum uric acid levels, and hypertension. Age and gender-wise distribution were compared in both control and diagnosed cases. In the diabetes group, blood sugar levels, BMI, and postprandial blood sugar levels were higher compared to the control group. Also, serum uric acid level was higher (3.2 to 7.9 $\mathrm{mg} / \mathrm{dl}$ ) in diabetic patients compared to control cases (2.5 to $5.2 \mathrm{mg} / \mathrm{dl}$ ) as shown in Table 1. Gender distribution of control and cases are shown in Table 2.

Hypertension, CAD, and family history of both controls and cases were compared and no statistical significance was found as shown in Table 3. Table-4 demonstrate the hyperuricemia association with DM in both control and cases with their proportion.
Table 1. Baseline parameters comparison in both study and controls cases.

\begin{tabular}{|l|l|l|}
\hline Variables & $\begin{array}{l}\text { Cases } \\
(\mathbf{n = 8 5})\end{array}$ & $\begin{array}{l}\text { Controls } \\
(\mathbf{n}=\mathbf{3 0})\end{array}$ \\
\hline Mean age (years) & $58.6 \pm 8.7$ & $56.5 \pm 7.6$ \\
\hline BMl $(\mathrm{kg} / \mathrm{m} 2)$ & $24.41 \pm 2.75$ & $21.13 \pm 2.32$ \\
\hline Waist-hip ratio $($ WHR) & $0.75-1.24$ & $0.67-1.13$ \\
\hline FBS $(\mathrm{mg} / \mathrm{dl})$ & $101-207$ & $85-130$ \\
\hline PBS $(\mathrm{mg} / \mathrm{dl})$ & $161-303$ & $122-199$ \\
\hline SUA $(\mathrm{mgt} / \mathrm{dl})$ & $3.2-7.9$ & $2.5-5.2$ \\
\hline
\end{tabular}

Table 2. Gender Distribution of Cases and Controls

\begin{tabular}{|c|c|c|}
\hline & Frequency (n) & Percentage (\%) \\
\hline \multicolumn{3}{|c|}{ Control group $(n=30)$} \\
\hline Male & 16 & 53.3 \\
\hline Females & 14 & 46.7 \\
\hline \multicolumn{3}{|c|}{ Cases Group ( $n=85)$} \\
\hline Male & 51 & 59.9 \\
\hline Females & 29 & 34.1 \\
\hline
\end{tabular}

Table-3. Cardio-vascular factors in controls and cases

\begin{tabular}{|l|l|l|l|}
\hline Factors & Cases $\mathbf{n}(\%)$ & Controls n (\%) & p-value \\
\hline Hypertension & $19(22.4)$ & $9(30)$ & 0.872 \\
\hline Smoking & $18(21.2)$ & $5(16.7)$ & 0.353 \\
\hline CAD history & $13(15.3)$ & $7(23.3)$ & 0.912 \\
\hline
\end{tabular}

Table 4. DM and hyperuricemia association in both controls and cases.

\begin{tabular}{|l|l|l|}
\hline Hyperuricemia & Cases n (\%) & Controls n (\%) \\
\hline Positive & $10(12.13)$ & $0(0)$ \\
\hline Negative & $75(87.87)$ & $30(100)$ \\
\hline
\end{tabular}

The uric acid means level increased from $4.29 \pm 0.81$ $\mathrm{mg} / \mathrm{dl}$ with a diabetic duration between 3 and 4 years to $4.59 \pm 0.99 \mathrm{mg} / \mathrm{dl}$ with a diabetic duration of 5 to 7 years. Furthermore, mean serum uric acid level reached $6.50 \pm 1.08$ in cases with diabetic duration 8 to 12 years as shown in Table/Figure-5.

Table-5. Association between Hyperuricemia and Duration of Diabetes (DOD).

\begin{tabular}{|l|l|l|l|}
\hline $\begin{array}{l}\text { DOD } \\
\text { (years) }\end{array}$ & Frequency $\mathbf{n}$ & $\begin{array}{l}\text { Hyperuricemia (Mean } \pm \\
\text { SD) } \\
(\mathbf{m g} / \mathbf{d l})\end{array}$ & $\begin{array}{l}\text { P- } \\
\text { Value }\end{array}$ \\
\hline $2-4$ & 15 & $4.29 \pm 0.81$ & $\begin{array}{l}0.356 \\
(\mathrm{~ns})\end{array}$ \\
\hline $5-7$ & 41 & $4.59 \pm 0.99$ & 0.001 \\
\hline $8-12$ & 29 & $6.50 \pm 1.08$ & 0.001 \\
\hline
\end{tabular}

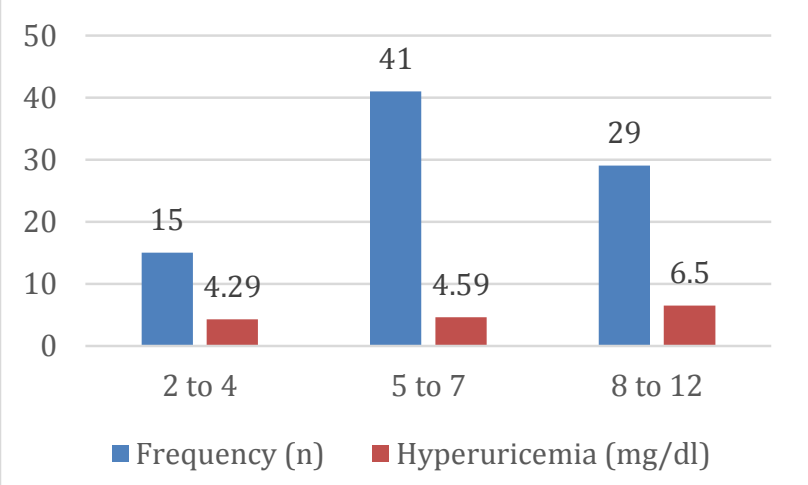

Figure 5. Association between Hyperuricemia and Duration of Diabetes (DOD). 


\section{DISCUSSION}

The current study was carried out with the purpose of evaluating type-Il diabetes mellitus, coronary atherosclerosis in patients and their association with serum uric acid levels. The study assessed the association between serum uric acids levels and type II diabetes mellitus. Hyperuricemia proportion among diabetic patients was $12.13 \%$ while none of the control cases had hyperuricemia. Another study reported a strong correlation between diabetes mellitus and serum uric acids and their complications [13]. In contrast to this study, one found no association among type II diabetes mellitus, ischemic stroke, CHD, and increased serum uric acids levels [14]. It was reported that uric acids have nothing to do with cardiovascular complications irrespective of the majority of studies reports [15]. Another study evaluated the association between type II diabetes mellitus risk factors and gout. It was found that type II diabetes mellitus higher risk exists among men with a high-risk profile of cardiovascular disease [16]. One study finds a reverse causality and challenged the nature of diabetes associated with serum uric acid and related complications of diabetes, especially artery corona disease [17]. Another study confirmed the complications of macro vascular, cerebral infarction, and CAD related to diabetes risks. Type II diabetes mellitus patients' cerebral infractions are caused by serum uric acid higher levels as concluded from more than twenty studies [18].

In the current study, Hyperuricemia proportion among diabetic patients was $12.13 \%$ while none of the control cases had hyperuricemia. The uric acid means level increased from $4.29 \pm 0.81 \mathrm{mg} / \mathrm{dl}$ with a diabetic duration between 3 and 4 years to $4.59 \pm 0.99 \mathrm{mg} / \mathrm{dl}$ with a diabetic duration of 5 to 7 years. Furthermore, mean serum uric acid level reached $6.50 \pm 1.08$ in cases with diabetic duration 8 to 12 years. Statistically, a significant association was found between serum uric acid and diabetic duration. Also, a positive correlation was found in hyperlipidemia, serum uric acid levels, and hypertension. Another study reported similar findings like our study with an additional finding that cardiovascular risk may not be transmitted due to hyperuricemia and hypertension [19-21]. A number of studies found similar results about a strong correlation between risk factors like hyperlipidemia and serum uric acid [22-24]. Similarly, a strong association between metabolic syndrome components and hyperuricemia was reported [25]. The concentration of elevated serum uric acids levels was overwhelmingly higher in cardiovascular risk and poor outcome. The present study correlated cardiovascular risk factors and diabetes duration. These risk factors were BMI, obesity, abnormal WHR, dyslipidemia, and hypertension. There was statistical significance between these two parameters. The limitation of the present study was small sample size and bias sampling technique.

\section{CONCLUSION}

Serum uric acid levels were found to be significantly higher in diabetics. Diabetic patients had hypertension, elevated serum uric acid levels, and high triglycerides with dyslipidemia. The rise in serum uric acid levels is proportional to the duration of diabetes.

\section{REFERENCES}

1. Rowley WR, Bezold C, Arikan Y, Byrne E, Krohe S. Diabetes 2030 insights from yesterday, today, and future trends. Popul Health Manag 2017;20:6-12

2. Waldfogel JM, Nesbit SA, Dy SM, Sharma R, Zhang A, Wilson LM, et al. Pharmacotherapy for diabetic peripheral neuropathy pain and quality of life: a systematic review. Neurology 2017:88:1958-67.

3. Pop-Busui R, Boulton AJ, Feldman EL, Bril V, Freeman R, Malik RA et al. Diabetic neuropathy: a position statement by the American Diabetes Association. Diabetes Care 2017;40:136-54.

4. Barrett EJ, Liu Z, Khamaisi M, King GL, Klein R, Klein BEK, et al. Diabetic microvascular disease: an endocrine society scientific statement. J ClinEndocrinolMetab 2017;102:4343-410.

5. Feldman EL, Nave KA, Jensen TS, Bennett DLH. New horizons in diabetic neuropathy: mechanisms, bioenergetics, and pain. Neuron diabetic neuropathy:

6. Trnkova L, Drsata J, Bousova I. Oxidation as an important factor of protein damage: implications for Maillard reaction. J Biosci 2015;40: 419-39.

7. Kanbay M, Segal M, Afsar B, Kang DH, Rodriguez-lturbe B, Johnson RJ. The role of uric acid in the pathogenesis of human cardiovascular disease. Heart 2013;99:759-66.

8. Puddu P, Puddu GM, Cravero E, Vizioli L, Muscari A. Relationships among hyperuricemia, endothelial dysfunction and cardiovascular disease: molecular mechanisms and clinical implications. J Cardiol 2012;59:235-42.

9. Shrivastava U, Misra A, Mohan V, Unnikrishnan R, Bachani D. Obesity, Diabetes and Cardiovascular Diseases in India: Public Health Challenges. Current diabetes reviews, 2016.

10. Kakkar R. Rising burden of DiabetesPublic Health Challenges and way out. Nepal journal of epidemiology, 2016; 6(2): 557-9.

11. Gupta R, Mohan I, Narula J. Trends in Coronary Heart Disease Epidemiology in India. Annals of global health, 2016; 82(2): 307-15.

12. Tripathy JP, Thakur JS, Jeet G, Chawla S, Jain S, Pal A, et al Burden and risk factors of dyslipidemia-results from a STEPS survey in Punjab India. Diabetes \& metabolic syndrome, 2016.

13. Katsiki N, Papanas N, Fonseca VA, Maltezos E, Mikhailidis DP. Uric acid and diabetes: Is there a link? Current pharmaceutical design, 2013; 19(27): 4930-7.

14. Keenan T, Zhao W, Rasheed A, Ho WK, Malik R, Felix JF, et al Causal Assessment of Serum Urate Levels in Cardiometabolic Diseases Through a Mendelian Randomization Study. Journal of the Diseases Through a Mendelian Randomization Study.
American College of Cardiology, 2016; 67(4): 407-16.

15. Nejatinamini S, Ataie-Jafari A, Qorbani M, Nikoohemat S,Kelishadi R, Asayesh $\mathrm{H}$, et al. Association between serum uric acid level and metabolic syndrome components. J Diabetes MetabDisord. 2015;14(1):1-7.

16. Shih M-H, Lazo M, Liu S-H, Bonekamp S, Hernaez R, Clark JM Association between serum uric acid and nonalcoholic fatty liver disease in the US population. J Formos Med Assoc. 2015;114(4):314-20.

17. Chang JB, Chen YL, Hung YJ, Hsieh $\mathrm{CH}$, Lee $\mathrm{CH}$, Pei D, et al. The role of uric acid for predicting future metabolic syndrome and type 2 diabetes in older people. J Nutr Health Aging. 2017;21(3):329-35.

18. Bonakdaran S, Kharaqani B. Association of serum uric acid and metabolic syndrome in type 2 diabetes. Curr Diabetes Rev. 2014;10(2):113-7.

19. Krishnan E, Pandya BJ, Chung L, Hariri A, Dabbous $O$. Hyperuricemia in young adults and risk of insulin resistance, prediabetes, and diabetes: a 15-year follow-up study. Am J Epidemiol. 2012;176(2):108-16.

20. Woyesa SB, Hirigo AT, Wube TB. Hyperuricemia and metabolic syndrome in type 2 diabetes mellitus patients at Hawassa university comprehensive specialized hospital, South West Ethiopia. BMC EndocrDisord. 2017;17(1):76.

21. Duman TT, Kocak MZ, Atak BM, Erkus E. Serum uric acid is correlated with $\mathrm{HbA} 1 \mathrm{c}$ levels in type 2 diabetes mellitus. Exp Biomed Res. 2018;1(1):6-9.

22. Wang J, Chen RP, Lei L, Song QQ, Zhang RY, Li YB, et al. Prevalence and determinants of hyperuricemia in type 2 diabetes mellitus patients with central obesity in Guangdong Province in China. Asia Pac J ClinNutr. 2013;22(4):590-8.

23. Peng TC, Wang CC, Kao TW, Chan JY, Yang YH, Chang YW, et al. Relationship between hyperuricemia and lipid profiles in US adults. Relationship between hyperuricemia and
Biomed Res Int. 2015;2015(2015):127596.

24. Lin X, Xu L, Zhao D, Luo Z, Pan S. Correlation between serum uric acid and diabetic peripheral neuropathy in T2DM patients. J NeurolSci 2018;385:78-82.

25. Abraham A, Breiner A, Barnett C, Katzberg HD, Lovblom LE, Perkins $\mathrm{BA}$, et al. Uric acid levels correlate with the severity of diabetic sensorimotor polyneuropathy. J NeurolSci 2017;379:94-8. 